\title{
Fiscal policy within a common currency area - growth implications in the light of neoclassical theory
}

\author{
Michał Konopczyński ${ }^{1}$
}

\begin{abstract}
We examine the long-run impact of fiscal policy on economic growth under the conditions of an economic and monetary union (EMU). The analysis is based on the neoclassical growth model of a small (in economic terms) open economy in an EMU. The core assumptions are perfect capital mobility, which results in identical interest rates across the EMU, and perfect mobility of goods, which leads to the convergence of price levels. The model is based on standard neoclassical assumptions, i.e., the output is determined by the Cobb-Douglas production function with a Harrodneutral technical progress and constant returns to scale, capital and labor receive their marginal products, etc. We show that a unique long-run equilibrium exists and is characterized by the socalled natural rate of growth. The necessary and sufficient conditions of global asymptotic stability form a system of three non-trivial inequalities. We argue that in modern economies, these conditions are satisfied, except perhaps for very short periods of time. Furthermore, we show that the golden rules of fiscal policy have the form of an alternative optimal policy that crucially depends on the relation between the real interest rate and the natural rate of growth and on the relations between five other autonomous parameters.
\end{abstract}

KEY WORDS: $\quad$ monetary union; golden rule; neoclassical growth theory; fiscal policy

JEL Classification: E13, E62, F43, H60

${ }^{1}$ Poznań University of Economics, Poland

\section{Introduction}

We are investigating the influence of fiscal policy on growth performance in the long run. The analysis is based on the neoclassical growth model of a small (in economic terms) country that participates in an economic and monetary union. Naturally, the model is inspired by the European Economic and Monetary Union. Nevertheless, the model rests on relatively ㅁ general assumptions; hence, (perhaps after minor ad-

Correspondence concerning this article should be addressed to: Michał Konopczyński, Poznań University of Economics, al. Niepodległości 10 , Poznań 61-875, Poland e-mail: michal.konopczynski@ue.poznan.pl justment) it may well be applied to almost any small economic entity with independent fiscal authorities in any monetary union. Therefore, our conclusions have the value of universality: they can be applied not only to existing monetary unions but also to those that have ceased to exist or will be born in the future.

The influence of fiscal policy on the long-run growth rate is the subject of many research papers, with the early contribution of Tobin (1965) to exogenous growth theory; there was another important paper by Barro (1990), who initiated a similar analysis in endogenous growth theory. Important contributions include Corsetti \& Roubini (1996); Futagami, Morita and Shibate (1993); Ghosh and Roy (2004); 
Greiner and Fincke (2009); Greiner and Semmler (2000); Groneck (2010); Minea and Villieu (2009). A review of the endogenous growth literature on fiscal policy is provided by Acemoglu (2008); Irmen and Kuehnel (2009).

The vast majority of endogenous growth theory (including all the papers listed above) is based on models of a closed economy with no foreign trade, no international capital flows and zero foreign debt. In the XXIst century's integrated world (especially in Europe), this model is an unacceptable oversimplification. However, few researchers have made the effort to extend closed-economy models to incorporate some aspects of openness. Recent examples of endogenous approaches are Fisher (2010) and Turnovsky (2009) and the references therein. In the case of exogenous growth theory, Carlberg (1997) is most likely the most prominent example; he describes a generalized version of an open economy model with perfect mobility of capital. We present a modification of his model: by imposing small-economy assumptions and introducing both domestic and international bonds, we obtained some new conclusions.

We are building on our earlier paper Konopczyński (2004), where we presented the neoclassical growth model without an explicit public sector. Now, we will distinguish two separate sectors: private and public. Generally speaking, the first sector produces goods and services that are sold in the market, and the income (after taxation) is partially saved and invested. In contrast, the public sector collects taxes and finances public expenditures. The budget deficit is financed exclusively by bonds, which are sold indiscriminately to domestic and foreign investors. In addition, we introduce foreign bonds, which are issued by foreign governments. Most of our other assumptions are similar to those in Konopczyński (2004). We prove that the dynamic equilibrium is unique and derive the necessary and sufficient conditions for its global asymptotic stability. In addition, we analyze the so-called golden rules regarding the fiscal parameters.

\section{A small economy in an EMU - basic assumptions}

An economic union requires free movement of goods and services as well as all factors of production. In a monetary union, all the member countries use a common currency, and furthermore, the monetary policy is conducted by a common central bank. We assume that the home country is small relative to the entire EMU. In particular, any changes in its economy are trivial from the EMU's point of view, i.e., they have negligible influence on the union-wide level of prices, wage rates, interest rates, and etc. Furthermore, we treat an EMU as a closed economy. Henceforth, the terms "abroad" and "foreign" refer to "all other EMU member countries".

The common currency facilitates the process of price convergence. For example, European Central Bank (2005); Sosvilla-Rivero and Gil-Pareja (2004); (2012); Wolszczak-Derlacz (2010) have found that differences in price levels in many sectors within the European Union are slowly decreasing. Therefore, we assume that in the long run, the equilibrium price levels are equal. The financial capital is assumed to be perfectly mobile. Consequently, the nominal interest rates are equal everywhere, and due to identical inflation rates, the real interest rates are also uniform across an EMU. For a small economy, the real interest rate is exogenous: $r=r *$. Due to perfect capital mobility, the supply of capital in a small economy instantaneously adjusts to the demand. Let $K$ be the domestic capital (the stock of capital used for production within the given country). Obviously, a certain part of $K$ is owned by foreign citizens. Let $K N$ be the national capital, i.e., all the capital that is owned by citizens of the country. Then, a certain part of $K N$ is allocated domestically, and the remainder is employed abroad. In addition, let $E$ be the net foreign assets, so that $K N=K+E$. Lastly, we assume that the labor $L$ is immobile because every country uses only its own stock of $L$. This assumption has strong empirical support. Researchers argue that in the case of the European Union, the mobility of people is low. Indeed, apart from obvious language and cultural differences, there are significant institutional barriers to migration within Europe (Kahanec, 2012; Meardi, 2012; Zimmermann, 2009).

\section{The public sector (government)}

By assumption, public revenues are proportional to the domestic output (which may be measured by the GDP):

$T=\tau Y$ 
where $0<\tau<1$. If the public expenditures exceed the revenues, the difference is financed by bonds that are sold (indiscriminately) to domestic and international investors. For simplicity, we assume that the specific risk associated with lending money to all governments in the EMU is uniform. Hence, the real interest rate on public bonds in all EMU countries is equal to $r$.

Let $B$ stand for the total outstanding public debt. Then, the budget deficit, which takes into account the interest payments on the outstanding debt, is equal to $G+r B-T$, where $G$ represents all the government expenditures. By assumption, all public expenditures are classified as consumption. We assume that the government makes a decision on the specific value of the ratio of the public deficit to the domestic output (GDP), i.e., it decides on the value of the (non-negative) parameter $\xi$, which is defined as follows:

$\xi=(G+r B-T) / Y$

A similar "fixed deficit" rule is used in some recent papers in the case of endogenous growth models of a closed economy, for example, Greiner, Semmler (2000), Groneck (2010), and Minea, Villieu (2009). It follows that

$G=T-r B+\xi Y$

Therefore, public expenditures are set according to the rule described by equation (3) with a crucial decision parameter $\xi$. The evolution of public debt is described by

$\dot{B}=G+r B-T=\xi Y$

A certain part of the new emission of bonds is purchased by foreign investors $(\theta)$, and the rest is bought by domestic agents:

$\dot{B}_{F}=\theta \xi Y$

$\dot{B}_{D}=(1-\theta) \xi Y$

where $0 \leq \theta \leq 1$. Of course, at every moment

$B=B_{D}+B_{F}$

where $B_{D}$ is the domestic debt and $B_{F}$ is the foreign debt of the government.

\section{The national income account}

The demand for domestic output consists of consumption and investment of the private sector, public expenditures and net exports, i.e.,

$Y=C+I+G+X-M$

The real national income consists of four elements:

- the compensation of labor, i.e., $w L$, where $w$ is the average wage rate, which is equal to the marginal product of labor

- the rent from the capital that is owned by citizens (the national capital), i.e., $w_{K} K N$, where $w_{K}=r+\delta$ is the rental rate of capital and $\delta$ is the rate of depreciation,

- the interest payments on domestic and foreign bonds, i.e., $r\left(B_{D}+O\right)$, where $O$ is the stock of foreign bonds held by the citizens of the country.

In the long-run state of equilibrium, the total revenues of firms are equal to the compensation of labor and the domestic capital $K$, i.e., firms make zero economic profits; for details see Konopczyński (2004), section 3 . Hence, the real disposable national income (which is equivalent to the GNP) can be expressed as follows:

$$
\begin{aligned}
Y_{d} & =w L+w_{K} K N+r\left(B_{D}+O\right)= \\
& =w L+w_{K}(K+E)+r\left(B_{D}+O\right)= \\
& =Y+w_{K} E+r\left(B_{D}+O\right)= \\
& =Y+(r+\delta) E+r\left(B_{D}+O\right)
\end{aligned}
$$

Therefore, the real disposable income is equal to the volume of the domestic output plus the revenues from the net foreign assets and the interest from domestic and foreign bonds. After taxation, this income is devoted to consumption $C$ and savings $S$. If $\gamma$ stands for the average propensity to save, then

$S=\gamma\left(Y_{d}-T\right)$

$C=(1-\gamma)\left(Y_{d}-T\right)$, where $0 \leq \gamma<1$

Equations (8) - (11) imply that

$C+S+T=C+I+G+X-M+(r+\delta) E+r\left(B_{D}+O\right)$ 
Combining the above with (4) and (7) and rearranging yields the following well-known identity:

$S-I=\dot{B}+Q$,

where $Q$ is the current account balance, i.e.,

$Q=X-M+(r+\delta) E+r O-r B_{F}$

Equation (12) is a very well-known macroeconomic identity: the excess of private savings over investment is used to finance both the public deficit and the current account balance (Dornbusch, 1980, p. 23).

The dynamics of domestic capital $(K)$ and national capital $(K N)$ are described by standard rules:

$\dot{K}=I-\delta K$

$K \dot{N}=I N-\delta K N$

To keep things simple, we assume equal rates of depreciation for all types of productive capital. Otherwise, we would have to explicitly describe the dynamics of each of the four types of capital (see above), which would seriously complicate the model. The net foreign assets are equal to the difference between the national capital and the domestic capital: $E=K N-K$. After taking into account (14) and (15), the evolution of $E$ is described as follows:

$\dot{E}=I N-I-\delta E$

By assumption, the national investment (which is financed by the citizens of the country and augments the national capital) is proportional to the disposable income net of taxes, i.e.,

$I N=\psi\left(Y_{d}-T\right)$, where $0 \leq \psi \leq 1$

The savings of the private sector add up to the financial and real assets held by the citizens. There are three types of assets in the model that citizens can invest in: national capital $(K N)$, domestic bonds and foreign bonds. Hence, the usage of savings is described as follows:

$S=I N+\dot{B}_{D}+\dot{O}$
Using (12) and (16), after rearranging we obtain

$\dot{O}=\dot{B}_{F}+Q-(\dot{E}+\delta E)$

This equation gives important insight into the model: it implies that if the government borrows from abroad a certain amount of money $\left(\Delta \dot{B}_{F}\right)$, then (if all the other conditions remain unchanged) the private sector will automatically lend the very same amount to these foreign governments (by purchasing $\Delta \dot{O}$ foreign bonds). Accordingly, the domestic stock of money remains unchanged. Therefore, any government decisions regarding the proportion $\theta$ cannot influence the domestic absorption. The very same mechanism applies to the current account balance: if the current account balance increases (exogenously) by a certain amount of money, then (ceteris paribus) an identical amount of money will be invested in foreign bonds. Thus, neither the domestic supply of money nor the aggregate demand for domestic output will change.

\section{The model}

By summarizing all the above assumptions and using standard neoclassical technology (see Konopczynski (2004), section 4), we obtain the following system of equations:

$$
\begin{aligned}
& \text { [i] } \quad r=\alpha\left(\frac{K}{A L}\right)^{\alpha-1}-\delta \text { where } 0<\delta<1 \\
& \text { [ii] } Y=K^{\alpha}(A L)^{\beta} \text { where } \alpha+\beta=1, \alpha, \beta>0 \\
& \text { [iii] } \quad T=\tau Y \text { where } 0<\tau<1
\end{aligned}
$$

[iv] $G=T-r B+\xi Y$ where $\xi \geq 0$

[v] $\dot{B}=\xi Y, \dot{B}_{F}=\theta \xi Y, \dot{B}_{D}=(1-\theta) \xi Y$ where $0 \leq \theta \leq 1$

[vi] $Y_{d}=Y+(r+\delta) E+r\left(B_{D}+O\right)$

[vii] $C=(1-\gamma)\left(Y_{d}-T\right)$ where $0 \leq \gamma<1$

[viii] $S=\gamma\left(Y_{d}-T\right)$

[ix] $Y=C+I+G+X-M$

[x] $Q=X-M+(r+\delta) E+r O-r B_{F}$

[xi] $I N=\psi\left(Y_{d}-T\right)$ where $0 \leq \psi \leq 1$ 
[xii] $\dot{K}=I-\delta K$

[xiii] $\dot{O}=S-I N-\dot{B}_{D}$

[xiv] $\dot{E}=I N-I-\delta E$

[xv] $\dot{A}=\sigma A$ where $\sigma>0$

[xvi] $\dot{L}=n L$ where $n>0$

with the following initial (endowment) conditions:

$K(0)=K_{0}>0, E(0)=E_{0}, B(0)=B_{0} \geq 0, B_{F}(0)=B_{F 0} \geq 0$, $B_{D}(0)=B_{0}-B_{F 0} \geq 0, \quad O(0)=O_{0}, \quad A(0)=A_{0}>0$, $L(0)=L_{0}>0$

It is convenient to rewrite the model by replacing the original variables with their ratios with respect to the effective labor $A L$. Hereafter, small letters indicate the original variables per effective labor (or pel, for short), e.g., $k=K / A L$. For example, equation [i] can be rewritten as

[i'] $r=\alpha k^{\alpha-1}-\delta$

and equation [xii] as

[xii'] $\dot{k}=i-\varphi k$

For simplicity, we assume that the real interest rate $r$ and the depreciation rate $\delta$ are constants. Then, the stock of domestic capital pel is fixed, which can be inferred from equation [i']:

$k=\left(\frac{\alpha}{r+\delta}\right)^{\frac{1}{\beta}}=$ const .

As a result, the domestic output pel is fixed as well. Because $\dot{k}=0$ at every moment, equation [xii'] implies that the domestic investment pel is always proportional to $k$ :

$i=\varphi k$, where $\varphi=n+\sigma+\delta$

Consequently, the taxes pel are also constant over time. Hence, the model can be rewritten in the following very convenient recursive form (see Konopczyński (2004), section 4): [k] $k=\left(\frac{\alpha}{r+\delta}\right)^{\frac{1}{\beta}}$ where $0<\delta<1$

$[y] \quad y=k^{\alpha}$

[i] $i=\varphi k$ where $\varphi=n+\sigma+\delta$

$[t] \quad t=\tau y$

[g] $g=t-r b+\xi y$ where $\xi \geq 0$

[b] $\dot{b}=\xi y-(n+\sigma) b$

$\left[b_{F}\right] \dot{b}_{F}=\theta \xi y-(n+\sigma) b_{F}$ where $0 \leq \theta \leq 1$

$\left[b_{D}\right] \dot{b}_{D}=(1-\theta) \xi y-(n+\sigma) b_{D}$

$\left[y_{d}\right] \quad y_{d}=y+(r+\delta) e+r\left(b_{D}+o\right)$

[c] $c=(1-\gamma)\left(y_{d}-t\right)$ where $0 \leq \gamma<1$

$[s] \quad s=\gamma\left(y_{d}-t\right)$

$[\mathrm{x}-\mathrm{m}] \quad x-m=y-c-i-g$

[q] $q=x-m+(r+\delta) e+r o-r b_{F}$

[ik] in $=\psi\left(y_{d}-t\right)$ where $0 \leq \psi \leq 1$

[o] $\dot{o}=s-i n-(1-\theta) \xi y-(n+\sigma) o$

[e] $\dot{e}=i n-i-\varphi e$

[A] $\dot{A}=\sigma A$ where $e(0)=e_{0}, \quad b(0)=b_{0} \geq 0$, $b_{F}(0)=b_{F 0} \geq 0, b_{D}(0)=b_{0}-b_{F 0} \geq 0, o(0)=o_{0}$, and $A(0)=A_{0}>0$.

\section{The dynamics of the model and the} (global) asymptotic stability of the steady state

In the basic version of the model (without government), the dynamics of the economy were described by a single linear differential equation (see eq. 30 in Konopczyński (2004), page 22). Explicitly introducing the government sector and foreign assets results in a significant complication of the dynamics, which is now described by a system of four (still linear) differential equations: 


$$
\begin{aligned}
\dot{b} & =f^{1}\left(b, b_{D}, o, e\right) \\
\dot{b}_{D} & =f^{2}\left(b, b_{D}, o, e\right) \\
\dot{o} & =f^{3}\left(b, b_{D}, o, e\right) \\
\dot{e} & =f^{4}\left(b, b_{D}, o, e\right)
\end{aligned}
$$

where the first two functions are given in $[b]$ and $\left[b_{D}\right]$ :

$$
\begin{aligned}
& f^{1}\left(b, b_{D}, o, e\right)=-(n+\sigma) b+\xi y \\
& f^{2}\left(b, b_{D}, o, e\right)=-(n+\sigma) b_{D}+(1-\theta) \xi y
\end{aligned}
$$

and $y=$ const. $>0$. The function $f^{3}$ can be obtained by substituting $[s]$, $[i k]$ and $\left[y_{d}\right]$ into equation $[o]$. Minor algebraic manipulation yields

$$
\begin{aligned}
& f^{3}\left(b, b_{D}, o, e\right)=(\gamma-\psi) r b_{D}+ \\
& +[(\gamma-\psi) r-(n+\sigma)] \cdot o+ \\
& +(\gamma-\psi)(r+\delta) \cdot e+ \\
& +(\gamma-\psi)(y-t)-(1-\theta) \xi y
\end{aligned}
$$

Obtaining the explicit form of the function $f^{4}$ requires similar substitutions and manipulations that utilize the following equations: $[e],[i n],\left[y_{d}\right]$, and $[t]$. Ultimately, we obtain

$$
\begin{aligned}
& f^{4}\left(b, b_{D}, o, e\right)=\psi r b_{D}+\psi r o+ \\
& +[\psi(r+\delta)-\varphi] \cdot e+\psi(1-\tau) y-i
\end{aligned}
$$

The dynamic equilibrium (or in other words, the steady state) is defined as the situation in which all the variables pel (except for $A$ and $w$ ) are constant over time. Technically, in the steady state the right-hand sides of equations (22) are equal to zero.

Proposition 1. (the proof is in the Appendix)

The necessary and sufficient conditions of global asymptotic stability are as follows:

$$
\left\{\begin{array}{l}
r(\delta \psi-\varphi \gamma)>(n+\sigma)(\delta \psi-\varphi) \\
r[\delta(\psi-\gamma)-3 \gamma(n+\sigma)]>-3(n+\sigma)[\delta(1-\psi)+2(n+\sigma)] \\
\gamma r<2(n+\sigma)+\delta(1-\psi)
\end{array}\right.
$$

Because (27) is quite complicated, it does not allow for straightforward conclusions unless one moves to empirical research and calibrates the model with data. However, one interesting feature of the model is that the stability (or instability) is independent of all the fiscal parameters. Substituting various values of the parameters into (27) leads to the somewhat pessimistic conclusion that for some realistic calibrations the equilibrium is unstable, whereas for other realistic calibrations it is stable. Nothing more conclusive can be derived from (27). However, from the economic point of view it is pointless to analyze unstable steady states. Whenever the economy is unstable (i.e., moving further away from the equilibrium), the decision parameters of the private sector $(\psi, \gamma)$ have to be adjusted. Otherwise, the economy breaks down. In this sense, it is pointless to analyze theoretical unstable steady states. Henceforth, we assume that the stability conditions (27) are satisfied, and in the next part of the paper, we only consider stable equilibria.

However, in the following section we will closely examine the stability conditions. In particular, we will try to assess whether these conditions are satisfied in the real world.

\section{The equilibrium}

Obviously, in the dynamic equilibrium (hereafter: the DE) all the variables pel are constants. Accordingly, all the original variables ( $Y, K, C, I$, and etc.) are growing exponentially at a constant rate that is equal to the natural rate of growth: $n+\sigma$ (except for $L$ and $A$, which grow at the exogenous rates $n$ and $\sigma$, respectively). In other words, all the variables expressed in units per capita ( $Y / L, C / L$, and etc.) are growing at a speed equal to the rate of technical progress $\sigma$. This rate also determines the speed of the growth of real wages (see Konopczyński (2004), section 6).

Before we examine the details, notice that four of the pel variables (domestic capital, output, domestic investment, and taxes) depend exclusively on the exogenous parameters and on the real (union-wide) interest rate $r$. This result follows directly from equations $[k],[y],[i]$, and $[t]$. Hence, the following equations are valid not only in equilibrium, but also elsewhere:

$$
\bar{k}=\left(\frac{\alpha}{r+\delta}\right)^{\frac{1}{\beta}}=\text { const. }
$$

$\bar{y}=\bar{k}^{\alpha}=$ const.

$\bar{i}=\varphi \bar{k}=$ const

$\bar{t}=\tau \bar{y}=$ const. 
Hereafter, bar symbols represent the values of variables in the dynamic equilibrium (the steady state). The equations $[b],\left[b_{F}\right]$, and $\left[b_{D}\right]$ lead directly to the steady state values of the public debt $\bar{b}$, which is decomposed into the domestic debt $\bar{b}_{D}$ and the foreign debt $\bar{b}_{F}$ :

$\bar{b}=\frac{\xi \bar{y}}{n+\sigma}, \quad \bar{b}_{D}=(1-\theta) \bar{b}, \quad \bar{b}_{F}=\theta \bar{b}$

As a result, in the DE the public debt pel is proportional to the level of government deficit (expressed as the ratio of the public deficit to the GDP $\xi$ ), and it is also inversely proportional to the natural rate of growth $n+\sigma$. Interestingly, $\bar{b}$ is independent of $\tau$, i.e., $\bar{b}$ does not depend on the size of the public sector. The index of indebtedness in the DE is equal to

$\frac{\bar{B}}{\bar{Y}}=\frac{\bar{b}}{\bar{y}}=\frac{\xi}{n+\sigma}$

The only decision parameter that influences the level of indebtedness in the $\mathrm{DE}$ is the government deficit parameter $\xi$. For illustration, suppose that the government plans to keep the ratio of the public debt to the GDP at a constant level of 50\%. According to (33), the deficit in relation to the GDP would have to be maintained at a stable level of one-half of the natural rate of growth. For example, if the long-run natural rate of growth $n+\sigma=3 \%$, then the ratio of the public deficit to the GDP has to be maintained at approximately $1.5 \%$. The obvious conclusion is that those countries that are characterized by high rates of growth (of population and technical progress) may safely allow themselves to have relatively high public sector deficits. In other words, the lower the rate of growth of the population is, the lower the safe level of the government deficit is. However, if the speed of technical progress is very high, then even relatively high levels of public deficit do not endanger a country's public finances.

It follows from equations $[g]$ and (32) that

$$
\bar{T}-\bar{G}=r \bar{B}-(n+\sigma) \bar{B}
$$

which means that in the DE, the primary budget surplus is just enough to cover the interest on public debt adjusted by the factor $(n+\sigma) \bar{B}$. In other words, the ratio of the primary surplus to the public debt in the $\mathrm{DE}$ is equal to the difference between the real interest rate and the natural rate of growth.
To find the stationary values of other important variables, we need to solve the system of equations that will result if we set the right-hand sides of equations (25) and (26) equal to zero. Solving the resulting system of equations yields the following values:

$\bar{o}=\frac{(\gamma-\psi)[\bar{y}-\bar{t}+(r+\delta) \bar{e}]}{n+\sigma-r(\gamma-\psi)}-\bar{b}_{D}$

$\bar{e}=\frac{\psi(1-\tau)(n+\sigma)-\frac{\alpha}{r+\delta} \varphi[n+\sigma-r(\gamma-\psi)]}{\varphi(n+\sigma-\gamma r)+\delta \psi(r-n-\sigma)} \cdot \bar{y}$

Then, substituting these values into other equations yields

$\bar{y}_{d}=\bar{y}+(r+\delta) \bar{e}+r\left(\bar{b}_{D}+\bar{o}\right)$

It follows from equation $[c]$ that $\bar{c}=(1-\gamma)\left(\bar{y}_{d}-\bar{t}\right)$. By taking into account formulas (32), (35) - (37) and rearranging the results in a strikingly simple formula for the DE consumption pel, we obtain that

$\bar{c}=\frac{\varphi(1-\gamma)(n+\sigma)(\beta-\tau)}{\varphi(n+\sigma-\gamma r)+\delta \psi(r-n-\sigma)} \cdot \bar{y}$

where the domestic output $\bar{y}=\left(\frac{\alpha}{r+\delta}\right)^{\frac{\alpha}{\beta}}=$ const. $>0$.

Formally, under our assumptions there is no guarantee that the steady-state consumption will be positive. Hence, (38) needs to be examined more closely. Notice that the first of the three conditions for stability (27) is equivalent to the following: $\varphi(n+\sigma-\gamma r)+\delta \psi(r-n-\sigma)>0$. Therefore, the denominator of the ratio in (38) is positive. Meanwhile, the numerator in (38) is positive if and only if $\tau<\beta$. The empirical estimates of $\beta$ are usually approximately 2/3 (Balistreri et al., 2003; Konishi \& Nishiyama, 2002; Willman, 2002). The level of taxation (at least in the OECD countries) only rarely approaches such a high level (though in some countries it is permanently above $50 \%$ ). Hence, it seems fair (at least on empirical grounds) to assume that

$\tau<\beta$

This assumption, along with all the others that were previously made, ensures positive consumption in the DE. The above can also be interpreted in the following (slightly perverse) way: if the government in a small 
economy under a monetary union raises the taxation too much (above $\beta$ ), then the private consumption will shrink to zero.

\section{The optimal fiscal policy}

In this section, we will search for the golden rules for fiscal policy, i.e., we will solve the following problem: what values of the fiscal parameters guarantee maximum consumption (per capita) in the DE. It is important to remember that the overall consumption consists of two elements: privately financed consumption $C$ and public expenditures $G$. Therefore, the optimization criterion is the total consumption per capita in the DE, i.e., $(\bar{C}+\bar{G}) / \bar{L}$. Notice that this ratio grows at a constant rate $\sigma$. Hence, the first (rather intuitive) conclusion is as follows: in the DE, the overall consumption grows more rapidly with a higher rate of technological progress.

Inasmuch as the technological level $A$ is exogenous, the maximization of consumption per capita $(C+G) / L$ is equivalent to the maximization of consumption pel $(c+g)$. Recall that in the DE, both public and private consumption pel are fixed according to the formula (38) and the following:

$\bar{g}=\left(\xi+\tau-\frac{\xi r}{n+\sigma}\right) \bar{y}, \quad$ where $\bar{y}=\left(\frac{\alpha}{r+\delta}\right)^{\frac{\alpha}{\beta}}$

First, notice that neither public nor private consumption depends on $\theta$. Therefore, the composition of the public debt is of absolutely no importance: it does not matter what share of the public debt is actually held by foreigners and what share remains in the hands of domestic investors. This conclusion is a straightforward implication of the balance identity (19).

Importantly, the steady-state consumption is a function of the level of the public deficit $(\xi)$ and the rate of taxation $(\tau)$. We examine these functions in detail. First, notice that $\frac{\partial \bar{c}}{\partial \xi}=0$, and therefore, private consumption in the DE is independent of the level of the deficit. However,

$\frac{\partial \bar{g}}{\partial \xi}=\left(1-\frac{r}{n+\sigma}\right) \cdot \bar{y}$

Clearly, three cases can be distinguished:

(a) If $r>n+\sigma$, then the level of the deficit $\xi$ should be as low as possible, (b) If $r<n+\sigma$, then the level of the deficit $\xi$ should be as high as possible,

(c) If $r=n+\sigma$, then the steady-state consumption per capita is independent of $\xi$.

Intuitively, in case (a), the cost of the public debt (the interest rate) is relatively high; hence, it is not worthwhile to borrow to finance public consumption. The exactly opposite situation occurs in case (b). In reality, all three of the parameters $r, n$, and $\sigma$ may change (and $r$ may actually be quite volatile). Thus, all three cases may occur in various countries in different periods and under varying circumstances.

Consider the level of taxation $\tau$. It follows from (38) that

$\frac{\partial \bar{c}}{\partial \tau}=\frac{-\varphi(1-\gamma)(n+\sigma)}{\varphi(n+\sigma-\gamma r)+\delta \psi(r-n-\sigma)} \cdot \bar{y}$

For any positive values of the parameters that satisfy stability conditions (27), this partial derivative is negative. Hence, the function $\bar{c}(\tau)$ is downward sloping. The smaller the redistribution of national income through the public sector is, the larger the private consumption in the DE is. However, because $\frac{\partial \bar{g}}{\partial \tau}=\bar{y}>0$, the higher the level of taxation is, the larger the public consumption in the $\mathrm{DE}$ is. Both of these observations are quite obvious. The interesting problem is determining which of these effects is stronger. In other words, uncovering what the relation of the total consumption in the DE is to the level of taxation is very revealing. The above derivatives can be combined into the following equation:

$\frac{\partial(\bar{c}+\bar{g})}{\partial \tau}=\frac{(r-n-\sigma) \cdot(\delta \psi-\varphi \gamma)}{\varphi(n+\sigma-\gamma r)+\delta \psi(r-n-\sigma)} \cdot \bar{y}$

If the $\mathrm{DE}$ is stable, the denominator of the above ratio is positive. Under this assumption, the sign of the partial derivative in (43) is determined by the signs of the two expressions in the numerator. Four cases can be distinguished (we neglect the special cases in which either one or both expressions in the numerator are equal to zero):

(a) If $r>n+\sigma$ and $\delta \psi-\varphi \gamma>0$, then the derivative in (43) is positive,

(b) If $r>n+\sigma$ and $\delta \psi-\varphi \gamma<0$, then the derivative in (43) is negative, 
(c) If $r<n+\sigma$ and $\delta \psi-\varphi \gamma>0$, then the derivative in (43) is negative,

(d) If $r<n+\sigma$ and $\delta \psi-\varphi \gamma<0$, then the derivative in (43) is positive.

Each of these cases is realistic from the empirical point of view, and none of them contradicts stability conditions (27). Therefore, the level of taxation should be either as high or as low as possible depending on the actual characteristics of the economy (i.e., the values of the parameters).

In practice, all four of these situations may occur in various countries in different periods because of the natural variability of the parameters (i.e., the real interest rate $r$, the savings rate $\gamma$, the rate of investment $\psi$, and the natural rate of growth $n+\sigma$ ).

To make things simpler and more tangible, notice that in real economies the rate of savings $\gamma$ is usually close to the rate of investment $\psi$. In that case, $\delta \psi-\varphi \gamma \approx(\delta-\varphi) \gamma=-(n+\sigma) \gamma<0$. Hence, in the real world cases (b) and (d) will occur much more often than the remaining ones. The first of these two cases can be interpreted as follows: if the real interest rate $r$ exceeds the natural rate of growth, then the level of taxation (as well as the public deficit, which was analyzed above) should be as low as possible to maximize the total consumption per capita in equilibrium. The opposite statement is true in case (d).

\section{Summary}

Introducing explicite the government sector allows for some new conclusions, and some of them significantly differ from the conclusions that were obtained in the simplified model (without government). For example, the necessary and sufficient conditions for the global asymptotic stability of the dynamic equilibrium are completely different than in the model without government. These conditions consist of three relatively complex inequalities that bind together virtually all the exogenous parameters of the economy; only the fiscal parameters are not connected thereby. This fact seems to be quite interesting, as it implies that the stability of an economy depends neither on the taxation rate nor on the deficit-to-GDP ratio.

It is relatively easy to come up with a set of parameters that violates the stability conditions. Nonetheless, we argue that any such set of parameters would be unrealistic because at least some of these parameters would diverge significantly from their real-world counterparts. For this reason, we argue that real-world economies easily satisfy the stability conditions.

Next, we have been seeking the "golden rules" for the fiscal policy parameters. Strictly speaking, we sought parameter values that maximize the total (private plus public) consumption per capita in a dynamic equilibrium. The "golden rules" of fiscal policy have the form of an alternative optimal policy that crucially depends both on the relation between the real interest rate and the natural growth rate and on the relations between five other independent parameters. Lastly, we have demonstrated that in a small open economy in an economic and monetary union, it is completely meaningless from the point of view of steady-state wealth whether the public debt is financed by domestic or foreign investors.

The model presented in our paper has some strengths (as well as weaknesses). First, it is based on very simple and general assumptions, and hence, it is very easy to analytically describe the state of equilibrium and investigate its properties. However, it is worth stressing that even in our very simple setting, the stability conditions are quite complex. Second, the dynamic equilibrium is globally asymptotically stable (for a very wide range of realistic values of the parameters), which enables straightforward applications of numerical methods for dynamic simulations of the transitory processes. For these two reasons, the model is perfectly suited to educational purposes. It can also serve as a starting point for more complex, applicable models.

\section{References}

Acemoglu, D. (2008). Introduction to Modern Economic Growth. Princeton, NY: Princeton University Press.

Balistreri, E. J., McDaniel, C. A., \& Wong, E. V. (2003). An Estimation of U.S. Industry-Level CapitalLabor Substitution Elasticities: support for CobbDouglas. North American Journal of Economics and Finance, 14 (3), 343-356.

Barro, R. J. (1990). Government spending in a simple model of economic growth. Journal of Political Economy, 98 (5), 103-125.

Carlberg, M. (1997). International Economic Growth, Heidelberg, Physica-Verlag. 
Corsetti, G., \& Roubini, N. (1996). Optimal government spending and taxation in endogenous growth models (Working Papers No. 5851). National Bureau of Economic Research.

Dornbusch, R. (1980). Open Economy Macroeconomics. New York, NY: Basic Books Inc.

European Central Bank. (2005). Monetary policy and inflation differentials in a heterogeneous currency area. ECB Monthly Bulletin, 5, 61-78.

Fisher, W. H. (2010). Relative Wealth, Growth, and Transitional Dynamics: The Small Open Economy Case. Macroeconomic Dynamics, 14, 224-42.

Futagami, K., Morita, Y., \& Shibate, A. (1993). Dynamic Analysis of an Endogenous Growth Model with Public Capital. Scandinavian Journal of Economics, 95 (4), 607-625.

Gandolfo, G. (1980). Economic Dynamics: Methods and Models (2nd ed.). Amsterdam: North-Holland.

Ghosh, S., \& Roy, U. (2004). Fiscal Policy, Long-Run Growth, and Welfare in a Stock-Flow Model of Public Goods. Canadian Journal of Economics, 37 (3), 742-756.

Greiner, A., \& Fincke, B. (2009). Public Debt and Economic Growth. Berlin: Springer.

Greiner, A., \& Semmler, W. (2000). Endogenous Growth, Government Debt and Budgetary Regimes. Journal of Macroeconomics, 22 (3), 363-384.

Groneck, M. (2010). A Golden Rule of Public Finance or a Fixed Deficit Regime? Growth and Welfare Effects of Budget Rules. Economic Modeling, 27 (2), 523-534

Irmen, A., \& Kuehnel, J. (2009). Productive Government Expenditure And Economic Growth. Journal of Economic Surveys, 23 (4), 692-733.

Kahanec, M. (2012). Labor Mobility in an Enlarged European Union (Discussion Paper No. 6485). The Institute for the Study of Labor.

Konishi, Y., \& Nishiyama, Y. (2002). Nonparametric Test for Translog Specification of Production Function in Japanese Manufacturing Industry. In iEMSR 2002 Conference Proceedings (pp. 597602). Manno: International Environmental Modelling and Software Society.

Konopczyński, M. (2004). Model wzrostu małej gospodarki w unii monetarnej. Ujęcie neoklasyczne [The growth model of a small economy in a monetary union. Neoclassical approach]. In E. Panek
(Ed.), Matematyka $w$ ekonomii [Mathematics in Economics]. Zeszyty Naukowe, 41 (pp. 7-42). Poznań: University of Economics.

Meardi, G. (2012). Union Immobility? Trade Unions and the Freedoms of Movement in the Enlarged EU. British Journal of Industrial Relations, 50 (1), 99-120.

Minea, A., \& Villieu, P. (2009). Borrowing to finance public investment? The "golden rule of public finance" Reconsidered in an Endogenous Growth Setting. Fiscal Studies, 30 (1), 103-133.

Sosvilla-Rivero, S., Gil-Pareja, S. (2004). Price Convergence in the European Union. Applied Economics Letters, 11 (1), 39-47.

Sosvilla-Rivero, S., Gil-Pareja, S. (2012). Convergence in car prices among European countries. Applied Economics, 44 (25), 3247-3254.

Tobin, J. (1965). Money and Economic Growth. Econometrica, 33 (4), 671-684.

Turnovsky, S. J. (2009). Capital Accumulation and Economic Growth in a Small Open Economy. Cambridge, UK: Cambridge University Press.

Willman, A. (2002). Euro Area Production Function and Potential Output: A Supply Side System Approach (Working Papers No. 153). European Central Bank.

Wolszczak-Derlacz, J., (2010). Does One Currency Mean One Price? Eastern European Economics, 48 (2), 87-114.

Zimmermann, K. F. (2009). Labor Mobility and the Integration of European Labor Markets (Discussion Paper No. 862). German Institute for Economic Research. 


\section{Appendix}

By making use of (23) - (26), equations of motion (22) can be rewritten in the following convenient form:

$$
\left[\begin{array}{l}
\dot{b} \\
\dot{b}_{\mathcal{D}} \\
\dot{\sigma} \\
\dot{e}
\end{array}\right]=\left[\begin{array}{cccc}
-(n+\sigma) & 0 & 0 & 0 \\
0 & -(n+\sigma) & 0 & 0 \\
0 & (\gamma-\psi) r & (\gamma-\psi) r-(n+\sigma) & (\gamma-\psi)(r+\delta) \\
0 & \psi r & \psi r & \psi(r+\delta)-\varphi
\end{array}\right]\left[\begin{array}{l}
6 \\
b_{\mathcal{D}} \\
o \\
e
\end{array}\right] \text {, }
$$

where $6=b-\bar{b}, 6_{\mathscr{D}}=b_{D}-\bar{b}_{D}, o=o-\bar{o}$, and $e=e-\bar{e}$ are the deviations from the steady state. Let $D$ symbolize the square matrix in (A1). Because the dynamics are described by linear system of equations (22), a closer examination of the properties of the matrix $D$ will provide us with the (necessary and sufficient) conditions of the global asymptotic stability of the steady state. Most likely the most convenient method is the Liénard-Chipart theorem (Gandolfo, 1980, p. 251). The characteristic equation of matrix $D$ is

$\operatorname{det}(D-\lambda I)=w_{0} \lambda^{4}+w_{1} \lambda^{3}+w_{2} \lambda^{2}+w_{3} \lambda+w_{4}=0$

We define the following determinants:

$$
R_{1}=w_{1}, \quad R_{2}=\left|\begin{array}{ll}
w_{1} & w_{0} \\
w_{3} & w_{2}
\end{array}\right|, \quad R_{3}=\left|\begin{array}{ccc}
w_{1} & w_{0} & 0 \\
w_{3} & w_{2} & w_{1} \\
0 & w_{4} & w_{3}
\end{array}\right|, \quad R_{4}=\left|\begin{array}{cccc}
w_{1} & w_{0} & 0 & 0 \\
w_{3} & w_{2} & w_{1} & w_{0} \\
0 & w_{4} & w_{3} & w_{2} \\
0 & 0 & 0 & w_{4}
\end{array}\right|
$$

According to the Liénard-Chipart theorem, the steady state is globally asymptotically stable if and only if the following conditions are satisfied:

(i) $w_{0}>0$, (ii) $w_{4}>0$, (iii) $w_{2}>0$, (iv) $R_{3}>0$, (v) $R_{1}>0$

Obviously, (i) is satisfied, as $w_{0}=1$. It can easily be demonstrated that

$w_{4}=\operatorname{det} D=(n+\sigma)^{2}[(n+\sigma-\gamma r) \varphi+\delta \psi(r-n-\sigma)]$

Therefore, condition (ii) is satisfied if and only if

$r(\delta \psi-\varphi \gamma)>(n+\sigma)(\delta \psi-\varphi)$

Inequality (iii) can be transformed to the following form:

$$
r[\delta(\psi-\gamma)-3 \gamma(n+\sigma)]>-3(n+\sigma)[\delta(1-\psi)+2(n+\sigma)]
$$

However, after some manipulation $R_{3}$ can be written as follows (the dots stand for very long and complex expressions):

$$
R_{3}=-2(n+\sigma)[\gamma r-2(n+\sigma)-\delta(1-\psi)] \cdot[\ldots]^{2}
$$

Hence, condition (iv) can be written in the following equivalent form:

$$
\gamma r<2(n+\sigma)+\delta(1-\psi)
$$


Furthermore,

$R_{1}=-\operatorname{tr} D=\gamma r-4(n+\sigma)-\delta(1-\psi)$

Notice that if (A6) is satisfied, then $R_{1}>0$. Therefore, condition (iv) implies condition (v).

To summarize, the necessary and sufficient conditions of stability (A3) can be reduced to the following (equivalent) system of inequalities:

$\left\{\begin{array}{l}r(\delta \psi-\varphi \gamma)>(n+\sigma)(\delta \psi-\varphi) \\ r[\delta(\psi-\gamma)-3 \gamma(n+\sigma)]>-3(n+\sigma)[\delta(1-\psi)+2(n+\sigma)] \\ \gamma r<2(n+\sigma)+\delta(1-\psi)\end{array}\right.$ 